\title{
From the Editor-in-Chief
}

\section{Kimon P. Valavanis ${ }^{1}$}

Published online: 24 April 2018

(C) Springer Science+Business Media B.V., part of Springer Nature 2018

\section{Dear Colleagues:}

We enter the last quarter of 2018. JINT has a new look (we hope you like it), and we try hard to clear the accepted papers queue, shortening the first submissionfinal acceptance timeframe. For your information, handling Editors receive periodically messages from my office, with kind reminders to accelerate paper processing. On occasion, I, myself, send reminders to reviewers who are close to the review deadline, or are beyond it. We realize how challenging it is to keep up with all the deadlines; we are all parallel processing our activities and tasks; regardless, we aim to help you, the authors, so this process will continue, and I am the one to blame.
In the meantime, we encourage you to consider JINT for publishing your work, and we are looking forward to reviewing your paper.

Enjoy the issue.

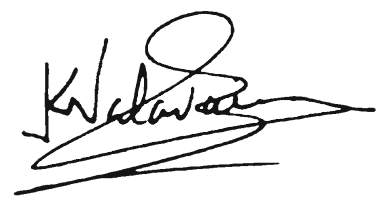

Kimon P. Valavanis Editor-in-Chief

Publisher's Note Springer Nature remains neutral with regard to jurisdictional claims in published maps and institutional affiliations.

Kimon P. Valavanis

Kimon.valavanis@du.edu

1 D. F. Ritchie School of Engineering and Computer Science, University of Denver, Denver, CO 80208, USA 